\title{
Investigar para interpretar. Anita de Melesio Morales
}

\author{
Sonia Machorro \\ sopranomachorro@hotmail.com \\ Cedart Frida Kahlo, INBAL
}

\begin{abstract}
"Hacer una buena edición es un acto de crítica que engarza de central el material musical en todos los niveles" (Grier, 2008. p.13).
\end{abstract}

\section{Introducción}

El objeto de este texto es mostrar 'una manera' de abordar el estudio y análisis del material musical desde dos roles, que muchas veces vemos muy lejanos: como investigador e intérprete. Pretendo mostrar la concatenación del rescate de la obra lírica del compositor $\mathrm{M}$. Morales con los elementos relevantes del análisis del texto musical y el texto dramático para ser llevado al escenario -en este caso particular a la sala de concierto-

Incluyo en él, elementos para complementar la interpretación musical: una breve biografía, los criterios de edición del material, un esbozo del entorno de composición de Anita, así como notas periodísticas escritas por el compositor y una tabla con la descripción de los manuscritos consultados. Además una sinopsis y análisis del libreto en el que incluyó los ejemplos musicales que habremos de escuchar.

Este trabajo es simple: una guía para abordar y desentrañar esta aria en particular, un germen para seguir buscando el modo a decuado de abordar el estudio de cada obra y que, al final, el hecho sonoro llegue de manera contundente al escucha.

\section{Biografía}

Melesio Morales empezó su formación musical en 1847 con Jesús Rivera y Río (sin fechar); en la academia de Agustín Caballero (1813-1886) siguió los cursos de la cátedra de acompañamiento de Felipe Larios (ca 1817-ca 1886). En 1855 se inició como discípulo en composición e instrumentación con Cenobio Paniagua (1821-1882) y, por recomendación de éste, aprendió cuestiones orquestales con Antonio
Valle (sin fechar). De 1866 a 1869 realiza, con Teodulo Mabellini (1817-1897) en Florencia, estudios de orquestación, armonía y contrapunto.

Su vida transcurría en dar clases, desde profesor a domicilio hasta en instituciones como la Sociedad Filarmónica Mexicana (Herrera y Ogazón, 1992) y el Conservatorio de ésta; como compositor de canciones, óperas, música sinfónica, para banda, obras para piano, coro, transcripciones y paráfrasis, además, como difusor de la música europea en México organizando, por ejemplo, el primer festival en honor a Beethoven (1770-1827) en el país en 1871. En su labor docente incursionó en la pedagogía y la educación musical para las que escribió los textos ABC, método teórico práctico de solfeo, y el manual Estética e historia de la música. Dentro de las instituciones musicales formó a Juan González Acevedo (1863-1929), Gustavo E. Campa (1863-1934) y Ricardo Castro (1864-1907) con quienes mantuvo fuertes enfrentamientos por la oposición que tenían a la corriente italiana y que formaron parte del llamado grupo de los seis. Además de sus alumnos particulares, dos destacan de manera contundente: Delfina Mancera (1854-1926), quien escribió el primer tratado de contrapunto y fuga en México y fue maestra de composición en el Conservatorio, y, por otra parte, Guadalupe Olmedo (1853-1889), quien compuso el Estudio clásico, considerado el cuarteto de cuerdas más antiguo escrito en México (Morales, 1999: pp.42-43).

Como comentarista escribe sobre las obras propias y temas musicales de su interés. Este hecho, se convertirá en una prueba de su 
preocupación por el gusto del público nacional aunque esto le acarreara situaciones difíciles, como la polémica con el regiomontano Eduardo Gariel (1860-1923), por la supremacía de la música italiana sobre la francesa, o por las críticas del historiador y literato Vicente Riva Palacio (1832-1896) en torno a su período de formación en Italia. A pesar de estas circunstancias de crítica y defensa de su labor creativa, siempre mantuvo un lugar preponderante dentro de la vida cultural y musical del país. Lucha por mostrar un arte mexicano tanto en la composición como en la interpretación. Su exigencia y labor musical lo llevaron a desempeñarse en un amplio ámbito de áreas. Su inmenso trabajo dejó una importante huella en la música mexicana. A los 70 años, Melesio Morales fallece en la ciudad de México el 12 de mayo de 1908.

\section{Edición de las arias}

Para James Grier (2008, pp.16-17) son cuatro los puntos principales para la edición:

1. Editar debe ser crítico por naturaleza;

2. Basar la edición en la investigación histórica;

3. Evaluar el texto musical a través de la investigación histórica;

4. Concebir el estilo musical como el juez de la evaluación crítica enraizada en el entendimiento histórico del trabajo.

Basada en estas directrices, la recopilación Melesio Morales Arias de ópera para soprano ha sido preparada con un fin práctico: volver a escuchar esta música. El ensamble para canto y piano, de fácil acceso en nuestros días, resulta la manera más sencilla de acercarlo a las salas de concierto. Además, se ha realizado una versión funcional que, no obstante, se apega al manuscrito y ofrece una traducción de los textos de las obras incluidas.

La parte medular de la transcripción está tomada de las reducciones de dichas obras. Sin embargo, se consultaron las partituras orquestales en los casos donde, por alguna razón, los manuscritos no son legibles. Se corrigieron cambios de compás y tonalidades a lo largo del aria y falsas relaciones de octava, tal como recomienda Grier en los puntos presentados. Se respetó la aparición de las ligaduras de fraseo y articulación, pero, en muchos casos, se hicieron sugerencias prácticas ya que un cierto número de éstas no se encuentran señaladas en los manuscritos. Además, se rectificó el manejo que da el compositor al uso del modo mayor-menor en ciertos pasajes y las alteraciones que este hecho conlleva: la eliminación de notas falsas. Se realizó el reacomodo de los textos de forma que el verso o los acentos tónicos de las palabras coincidan con la estructura musical, $y$, la adaptación de compases que contienen un mayor o menor número de notas permitidas. Se eliminaron algunas repeticiones y/o se elaboraron finales optativos en la presente edición, ya que en el manuscrito original las arias se enlazan con otras secciones que concluyen en dúos, tríos u otros ensambles. También se incluye un apéndice indicando cambios específicos al manuscrito original.

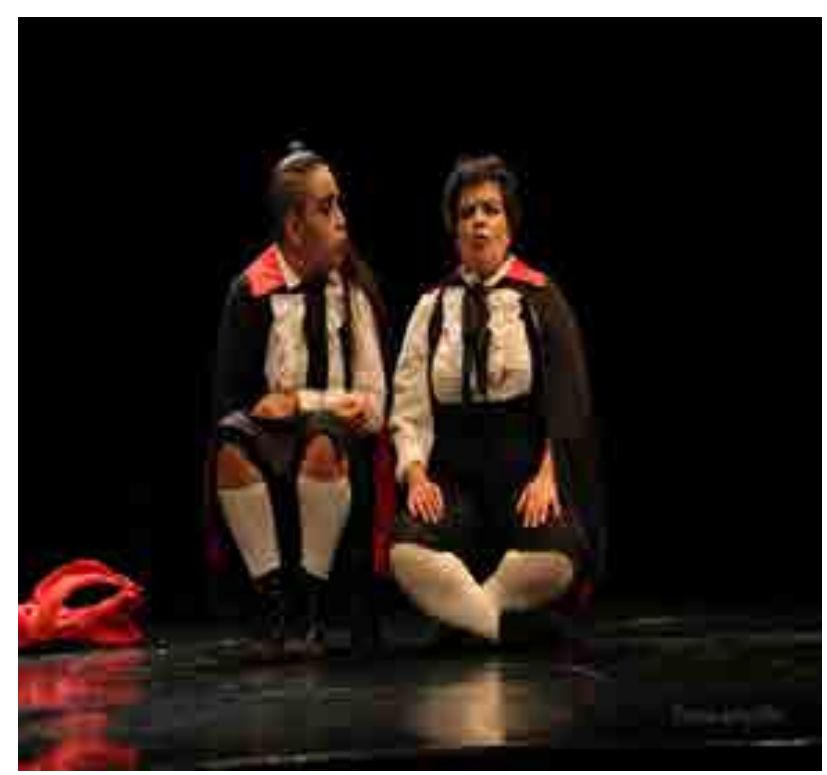

Ana Isabel Campillo 
Tabla 1. Producción operística del compositor

\begin{tabular}{|c|c|c|c|c|c|c|}
\hline Ópera & Género & $\begin{array}{c}\text { Texto } \\
\text { original }\end{array}$ & Libretista & Dedicatoria & Fechada & Estreno \\
\hline Romeo: & $\begin{array}{l}\text { Drama } \\
\text { serio en dos } \\
\text { actos }\end{array}$ & $\begin{array}{l}\text { Romeo and } \\
\text { Juliet } \\
\text { William } \\
\text { Shakespeare }\end{array}$ & $\begin{array}{l}\text { Felice } \\
\text { Romani } \\
(1788-1865)\end{array}$ & $\begin{array}{l}\text { Trinidad } \\
\text { Morales }\end{array}$ & 1860 & $\begin{array}{l}\text { Teatro } \\
\text { Nacional } \\
27 \text { enero } 1863\end{array}$ \\
\hline Ildegonda & $\begin{array}{l}\text { Drama en } \\
\text { dos actos y } \\
\text { cuatro } \\
\text { partes }\end{array}$ & $\begin{array}{l}\text { Temistocle } \\
\text { Solera } \\
(1815-1878)\end{array}$ & $\begin{array}{l}\text { Temistocle } \\
\text { Solera }\end{array}$ & $\begin{array}{l}\text { Elisa } \\
\text { Tomassi }\end{array}$ & 1863 & $\begin{array}{l}\text { Teatro } \\
\text { Imperial } \\
23 \text { enero } 1866\end{array}$ \\
\hline $\begin{array}{l}\text { Gino Corsini } \\
\text { ossia la } \\
\text { maledizzione }\end{array}$ & $\begin{array}{l}\text { Drama } \\
\text { lirico en } \\
\text { cuatro actos }\end{array}$ & $\begin{array}{l}\text { Temistocle } \\
\text { Solera }\end{array}$ & $\begin{array}{l}\text { Temistocle } \\
\text { Solera }\end{array}$ & $\begin{array}{l}\text { Ramón } \\
\text { Terreros }\end{array}$ & $\begin{array}{l}1867- \\
1869\end{array}$ & $\begin{array}{l}\text { Gran Teatro } \\
\text { Nacional } 14 \\
\text { julio } 1877\end{array}$ \\
\hline Cleopatra & $\begin{array}{l}\text { Drama } \\
\text { épico en } \\
\text { cuatro actos }\end{array}$ & $\begin{array}{l}\text { Anthony and } \\
\text { Cleopatra } \\
\text { William } \\
\text { Shakespeare }\end{array}$ & $\begin{array}{l}\text { Antonio } \\
\text { Ghislanzoni } \\
\text { (1824-1893) }\end{array}$ & $s / d$ & 1873 & $\begin{array}{l}\text { Gran Teatro } \\
\text { Nacional } \\
14 \text { noviembre } \\
1891\end{array}$ \\
\hline Anita & $\begin{array}{l}\text { Drama } \\
\text { lírico en un } \\
\text { acto } y \\
\text { catorce } \\
\text { escenas }\end{array}$ & $\begin{array}{l}\text { Enrico } \\
\text { Golisciani } \\
(1848-1919)\end{array}$ & $\begin{array}{l}\text { Enrico } \\
\text { Golisciani }\end{array}$ & Porfirio Diaz & 1900 & $\begin{array}{l}\text { Conservatorio } \\
\text { Nacional de } \\
\text { Música de } \\
2010\end{array}$ \\
\hline
\end{tabular}

Hay referencia a dos óperas Carlo Magno de la que solo sobrevive el tercer acto y algunas acuarelas de la escenografía y Silvia cuya mención figura en Mi libro verde, pero desafortunadamente no hay documentos en el archivo del compositor.

\section{Anita}

La música de Melesio Morales tuvo gran impacto en el público decimonónico, así como en sus alumnos y críticos de la época, que encontraron en su obra dramática una fuente de inspiración para el enriquecimiento del ambiente operístico nacional. Su arraigada formación bajo los cánones de la escuela italiana, no le permitieron romper con los lineamientos estilísticos de esta corriente y por esta causa, es difícil establecer si con Morales y sus contemporáneos, surge un movimiento de ópera mexicana, ya que no existe un estilo de composición, dentro de este género, que se pueda jactar de ser totalmente original. Don Melesio fue uno de los muchos impresionados por la música de Richard Wagner (1813-1833) y meditó durante cierto tiempo los conceptos novedosos como el Leitmotiv, las complejas orquestaciones de grandes dotaciones polifónicas y la indefinición tonal.

Por otra parte, las posibilidades del verismo en la acción dramática de personajes de la vida cotidiana que vio en las obras de Mascagni también lo influenciaron (Morales, 1999; p. 46). Así, el impacto de todos estos acontecimientos llevaron al autor a abandonar el uso de personajes legendarios, en favor de protagonistas ordinarios y en contextos culturales contemporáneos. Sin embargo, Anita junto con otras composiciones dramáticas de autores en el mismo período, constituye una de las primeras producciones operísticas que voltearon la mirada hacia la delimitación de un sentimiento patriótico basado en el uso de un argumento centrado en un tema nativo, que, visto dentro de un complejo 


\section{INFORMES DE INVESTIGACIÓN}

Me anima solamente el deseo

conjunto, encaminó hacia la búsqueda de una identidad nacional.

Esta obra lírica se terminó alrededor de 1900, en ésta exploró nuevos caminos de estructura y contenido, ya que es una obra con pocos recursos escénicos y escasos personajes y, a pesar de que el libreto está concebido en italiano, por primera vez utilizó una temática nacional e introdujo algunas melodías de corte popular y se adhirió a la imperiosa búsqueda patriótica de la nueva nación cosmopolita.

Anita se programó para las temporadas de 1903 y 1904, pero el objetivo del compositor no se cumplió: su última obra lírica no fue llevada a escena en vida del autor. En pleno siglo XXI se dio a conocer la obra en concierto en 2000 y en 2002, una en el Conservatorio Nacional de Música y otra en la sala Manuel M. Ponce del Palacio de las Bellas Artes. Se estrenó en 2010 en el Conservatorio Nacional de Música, con motivo de las celebraciones del 200 aniversario de la Independencia y del centenario de la Revolución de este país.

En una carta al "El Tiempo" en octubre de 1903 Morales escribe:

Es pues, bajo el dominio de mi criterio respecto de las propiedades que reconozco en el arte músico y son únicamente las de agradar y conmover, que he escrito mi Anita, procurando adaptarla a la idiosincrasia del público de México, que es al que debo lo que soy y a quien directamente he consagrado durante mi vida mis labores profesionales, guiándome en la parte artístico- científica, por las doctrinas generadoras y tradicionales, con sus modificaciones en turno, de la célebre Escuela italiana, que he cultivado y difundido con afán y cariño, seguro de que su especial modo de ser, consistente en el predominio de la melodía conceptuosa, es el que más se amolda a las tendencias y gustos nacionales.

Además, no pierde la oportunidad de hacer política: -y acaso la esperanza- de agradarlo [al público], esperanza que fundo en el simpático asunto que he elegido, idea sobre una fecha grata y memorable para todo mexicano, y de cuya jornada fue protagonista nuestro prestigiado y amado Presidente general Porfirio Díaz, quien - dígolo con gusto desde luego - se ha dignado aceptar la dedicatoria que le he hecho de mi composición.

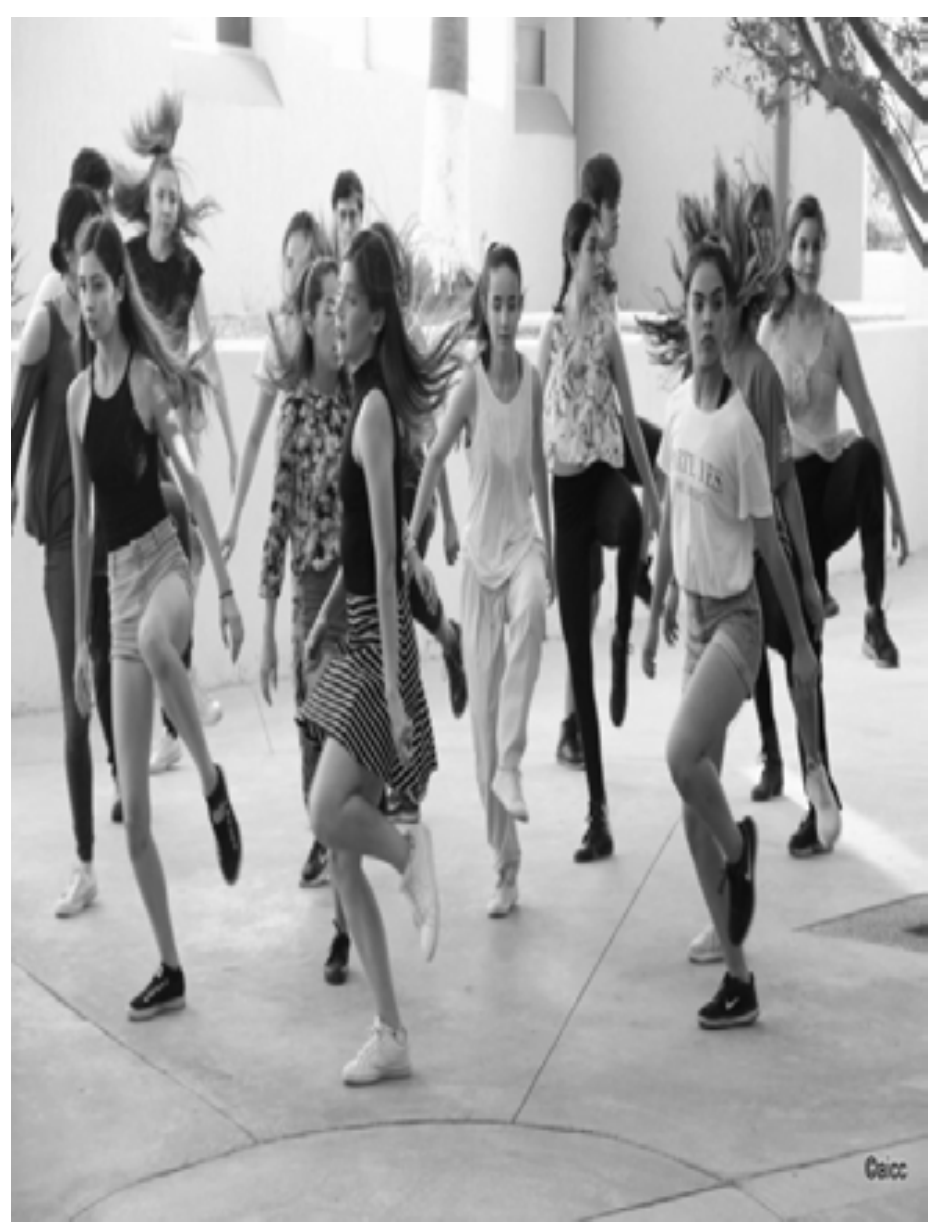


Tabla 2. Manuscritos existentes de Anita en el archivo de Melesio Morales

\begin{tabular}{|c|c|c|c|c|c|c|}
\hline Obra & Género & Dotación & $\begin{array}{c}\text { Tamaño } \\
\text { (cm.) }\end{array}$ & Fojas & Número & Descripción \\
\hline Anita & ópera & $\begin{array}{l}\text { canto y } \\
\text { orquesta }\end{array}$ & $28 \times 35$ & 269 & 1 de 7 tomo 1 & encuadernado $\mathrm{ms}$ \\
\hline Anita & ópera & $\begin{array}{l}\text { canto } y \\
\text { piano }\end{array}$ & $28 \times 35$ & 128 & $2 \mathrm{de} 7$ tomo 2 & encuadernado $\mathrm{ms}$ \\
\hline Anita & ópera & $\begin{array}{l}\text { canto } y \\
\text { piano }\end{array}$ & $27 \times 33$ & 142 & $\begin{array}{l}3 \text { de } 7 \text { incluye } \\
\text { particellas } \\
\text { instrumentales ms }\end{array}$ & encuadernado ms \\
\hline Anita & opera & texto & $10.5 \times 16$ & 83 & 4 de 7 libreto & encuadernado $\mathrm{ms}$ \\
\hline Amita & ópera & $\begin{array}{l}\text { canto } y \\
\text { piano }\end{array}$ & $27 \times 33$ & 144 & $\begin{array}{l}5 \text { de } 7 \text { particellas } \\
\text { canto y piano }\end{array}$ & encuadernado ms \\
\hline Anila & opera & $\begin{array}{l}\text { canto } y \\
\text { piano }\end{array}$ & $27 \times 33$ & 153 & 6 de 7 suggeritore & encuadernado $\mathrm{ms}$ \\
\hline Anita & ópera & $\begin{array}{l}\text { canto } \mathrm{y} \\
\text { piano }\end{array}$ & $27 \times 33$ & 272 & 7 de 7 concertatore & encuadernado $\mathrm{ms}$ \\
\hline
\end{tabular}

Tabla 3. La orquestación de Anita

\begin{tabular}{|c|c|c|c|c|}
\hline 3 Flautas/Piccolo & 3 Trompetas & Piano & 4 Cornos & Arpa \\
\hline Corno ingles & Tuba & Oboe & 3 Trombones & Orquesta de cucrdas \\
\hline 2 Fagotes & Gran casa & 2 Clarinetes & Timbales & \\
\hline
\end{tabular}

\section{Tabla 4. Libreto de Anita}

\begin{tabular}{|l|l|l||}
\hline Personaje & Caracteristicas & \multicolumn{1}{c|}{ Voz } \\
\hline Anita & Hija de un miembro del ejército mexicano & Soprano \\
\hline Gastone D'Auvray & Oficial francés & Tenor \\
\hline Manuelo & Guardia nacional y hermano de Anita & Bajo \\
\hline Rodrigo & Oficial y pretendiente de Anita & Baritono \\
\hline Coro & & Infantil y mixto \\
\hline
\end{tabular}

\section{Sinopsis}

La ópera inicia con una imagen del campo de batalla en donde, de la noche del 4 al amanecer del 5 de mayo, luchan el ejército francés contra el mexicano. En el contingente nacional se encuentran Manuelo y Rodrigo; dos oficiales que luchan mientras Anita, escuchando el fragor de la batalla, lamenta no poder combatir en defensa de su patria e implora la victoria del ejército mexicano. Casi al término de la batalla llega a su casa un enemigo herido. Anita reconoce a Gastone, el extranjero de quien se enamoró después de que le salvó la vida al rescatarla de un grupo de bandoleros. Anita alivia las heridas 


\section{INFORMES DE INVESTIGACIÓN}

del oficial francés y lo esconde en su habitación, pues Manuelo y Rodrigo regresan a celebrar la victoria. Durante la celebración Rodrigo pide la mano de Anita en matrimonio como recompensa por haber matado al padre de Gastone, quien en una batalla previa había asesinado al padre de la joven. Manuelo apoya a Rodrigo, aunque ella les pide que esperen al día siguiente para que les dé una respuesta. Entre el alboroto de la celebración, Gastone escucha las ofensas que se hacen contra su patria e indignado sale de su escondite para saldar la afrenta; inmediatamente es sometido por los soldados que pretenden darle muerte, pero por la rápida intervención de Anita, posponen la ejecución para la madrugada siguiente y se llevan al francés prisionero. Después, Anita logra entrar a la celda disfrazada con el uniforme de su hermano y convence a Gastone de huir. Al tiempo que el galo parte, le promete volver por ella. Rodrigo entra en el calabozo y descubre que Anita ha ayudado al prisionero a escapar. Furioso saca su arma, dispara y la asesina. Para terminar, entra Porfirio Díaz a la plaza de Puebla. El coro canta el "Himno a la Patria" basado en el texto del Himno Nacional Mexicano; el tema de este es una variación de su primera frase melódica.

\section{Análisis del libreto}

Tomando como base el análisis literario se puede concluir que:

\section{Tabla 5. Análsis literario del libreto de Anita}

\begin{tabular}{|l|l|l|l|}
\hline Género & Realista & Estilo & Costumbrista \\
\hline Tono & Neufro & Idioma & Italiano \\
\hline \multirow{2}{*}{ Tema } & Amor & Conflicto & $\begin{array}{l}\text { Amor y traición a la } \\
\text { patria }\end{array}$ \\
\hline Número de actos & Uno & Trayectoria dramática & Toma de conciencia \\
\hline \multirow{2}{*}{ Protagonistas } & Anita, hija de un miembro del ejército mexicano \\
\cline { 2 - 4 } & Gastone D'Auvray, oficial francés \\
\hline Antagonistas & Rodrigo, oficial y pretendiente de Anita \\
\hline Efecto en el püblico & Reflexión & \\
\hline
\end{tabular}

todos estos elementos están representados en al aria, los primeros puntos a resaltar son:

1. Tema del aria: Amor

2. Sujeto: Joven Caudillo

3. Connotación: Adjetivos (luz, color, sentido estético)

4. Objetivo: Resolver conflicto amoroso-patriótico

5. Acción:Verbos conjugados

\section{Contexto del aria}

\section{Antecedentes}

La guerra contra los franceses reclama a Manuelo y Rodrigo, oficiales del ejército mexicano. Anita despide al hermano y al pretendiente; lamenta no ser hombre y, así, poder tomar las armas a su lado. Afuera se oye el fragor de la batalla y la joven pide a la virgen protección para los valientes que acuden al combate.

Aria 
La prima volta un fascino, inserta en el cuadro primero del acto único de la obra, se desarrolla en la sala de la casa de Anita: la moza se encuentra pensando en Gastone, oficial francés, por quien está en gran conflicto ya que el joven representa al enemigo pero le inspira amor.

Extensión vocal

Se requiere el siguiente rango vocal para interpretar el personaje que aparece en escena.

\section{Imagen 1. Extensión vocal del personaje Anita}

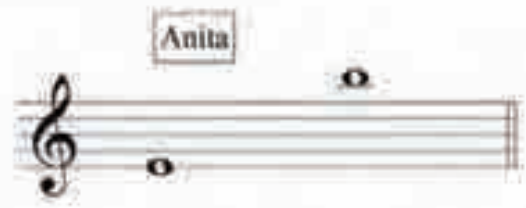

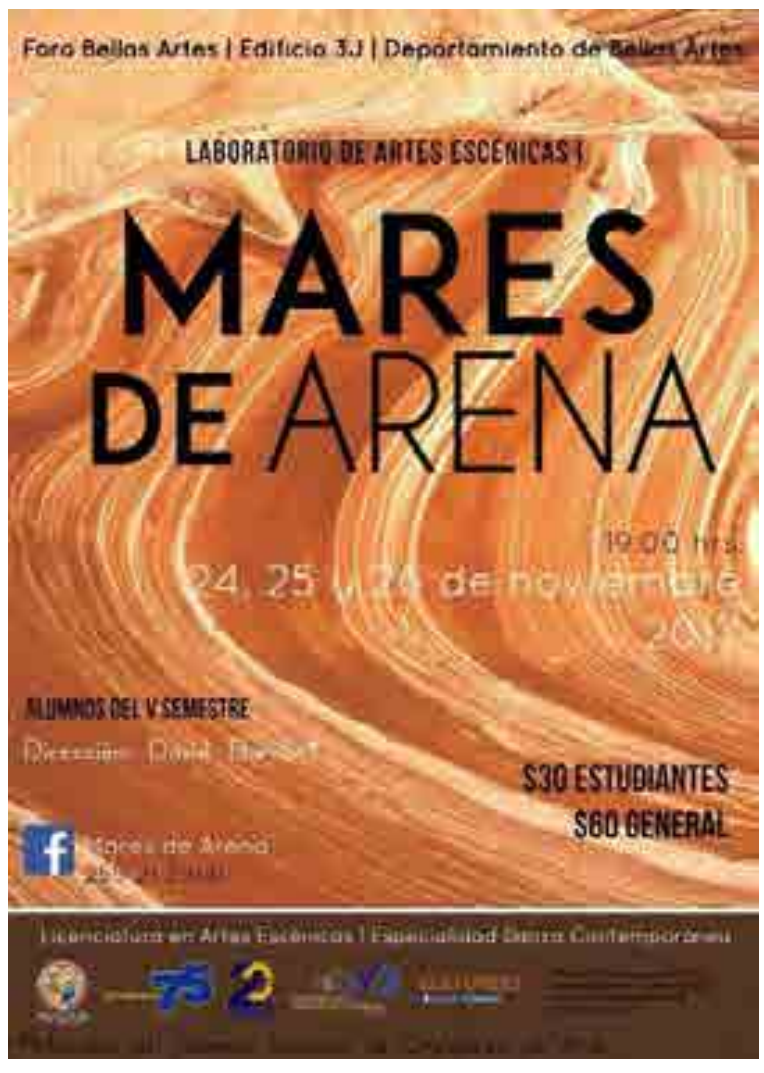

Mares de Arena

Traducción La prima volta un fascino

\begin{tabular}{|c|c|}
\hline La prima volta un fascino. & Por primera ves una fascinación. \\
\hline $\begin{array}{l}\text { ANiTA } \\
\text { Eppure. Ohime! Tal volta allor che Vora e } \\
\text { folta, tacita to veglio ignara, d'una dolee } \\
\text { parola, Come mi sento trista! Come mi sento } \\
\text { sola. E al di ripenso. Al memore di cuanto } \\
\text { più inferiva, su noi le truce ostil baldanza. }\end{array}$ & $\begin{array}{l}\text { ANITA } \\
\text { ¡No obstante, pobre de mi, qué cambio ahora } \\
\text { que la hora es fatal, yo estoy callada, en vela y } \\
\text { sin noticias, sin una dulce palabrat iQué triste } \\
\text { me siento, estoy tan sola! Hoy reflexiono. Con } \\
\text { este recuerdo de cuánto más se deducia, siento } \\
\text { sobre nosotros la cruel y hostil osadia. }\end{array}$ \\
\hline $\begin{array}{l}\text { Nel villaggio scesa già noi fancinlle, un'orda } \\
\text { ebra ghermiva, ma un giovin duce forse } \\
\text { nostra difesa e a noi salvo clemente, é vita e. } \\
\text { onor. }\end{array}$ & $\begin{array}{l}\text { Del caserio bajaban los muchachos, un grupo de } \\
\text { ebrios me atrapó, pero un joven caudillo llegó en } \\
\text { nuestro auxilio y clemente nos salvó, en vida y } \\
\text { honor. } \\
\text { Por primera vez vence a mi corazón una nueva }\end{array}$ \\
\hline $\begin{array}{l}\text { La prima volta un fascino novo mi vinse el } \\
\text { core e del prode l'immagine sculta rimane in } \\
\text { me. Ah! Si, cut dentro io porto diessa } \\
\text { pasione il fuoco it cui fin mi spaventa e } \\
\text { giungera si fra poco. }\end{array}$ & $\begin{array}{l}\text { fascinneión y la imagen valerosa permanece } \\
\text { esculpida en mi. iAh, si, aqui dentro tlevo la } \\
\text { pasión y el fuego que me asusta y que se le unira } \\
\text { dentro de poco tiempo! } \\
\text { El mio es un cruel destino iAy, de mi!, ¿Por qué } \\
\text { te vi joven extranjero? }\end{array}$ \\
\hline $\begin{array}{l}\text { io } \\
\text { vidi giovane stra }\end{array}$ & \\
\hline
\end{tabular}




\section{INFORMES DE INVESTIGACIÓN}

Aparato crítico

\begin{tabular}{|c|c|c|}
\hline Compás & En el original & En la edición \\
\hline 57 & Piano mi. Fa & Piano m.i. Sol $4, \mathrm{Si}$ \\
\hline $61-62$ & Voz reacomodo del texto & $\begin{array}{l}\text { Voz texto des Si 5, tin Sol } \\
\text { Sol 5. La 5, Si } 5\end{array}$ \\
\hline $61-67$ & $\begin{array}{l}\text { Piano reacomodo de notas que forman el } \\
\text { trémolo }\end{array}$ & Piano m.i. \\
\hline 69 & Texto lo: & Texto $\pi$ \\
\hline $69-70$ & $\begin{array}{l}\text { Piano reacomodo de notas que forman el } \\
\text { trémolo }\end{array}$ & \\
\hline $72-75$ & $\begin{array}{l}\text { Piano reacomodo de notas que forman el } \\
\text { trémolo }\end{array}$ & \\
\hline $113-115$ & $\begin{array}{l}\text { Piano m.i. reorganización disposición de } \\
\text { acordes }\end{array}$ & Piano mi Mi 3, Si 3, Si 5,Sol \\
\hline
\end{tabular}

\section{Ejemplo 1. Edición Crudel destin}
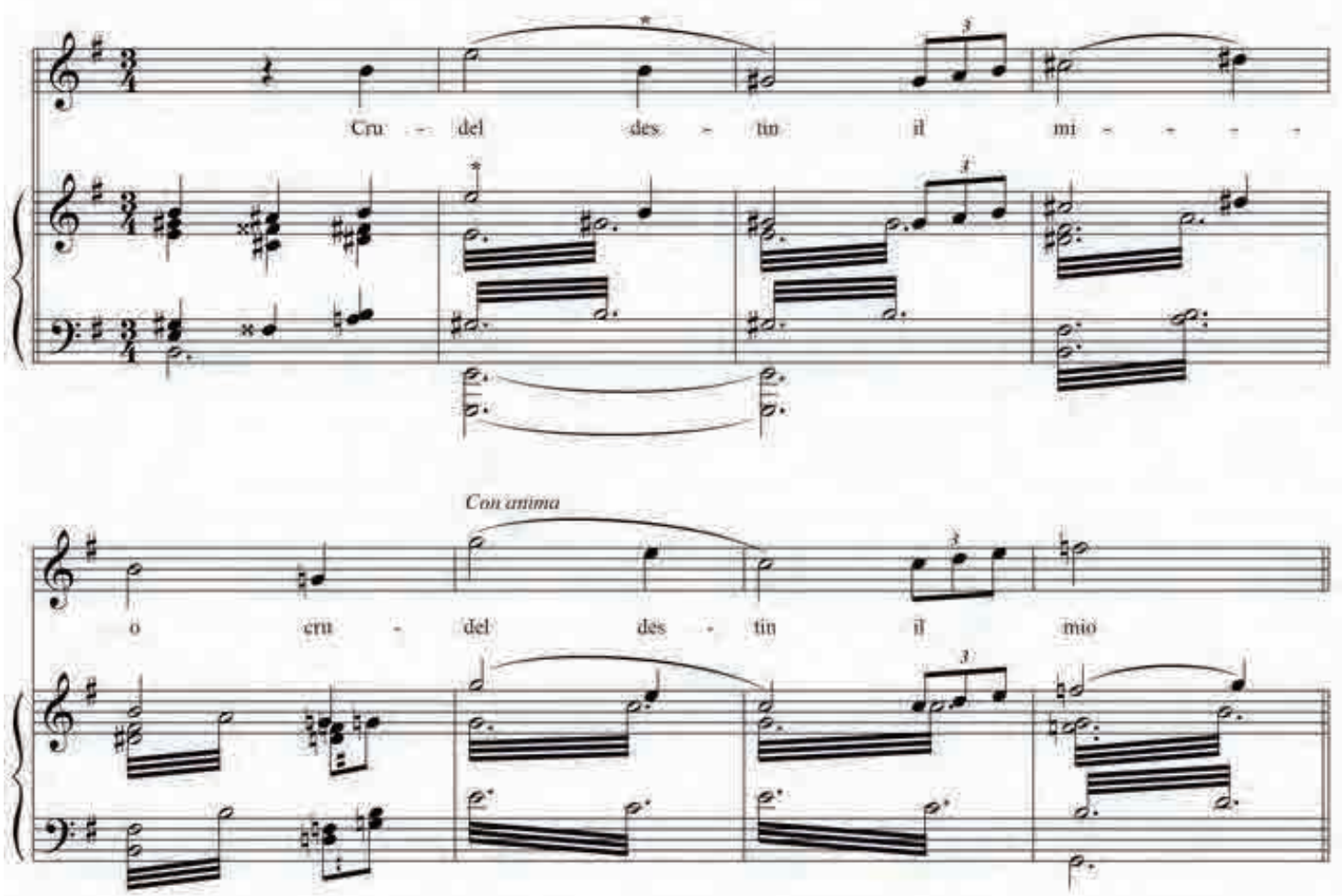

Análisis texto y música Eppure...Ohimè!

\section{Eppure...Ohime!}

Tal volta allor che l'ora é folta Tacita io veglio ignara d'una dolce parola. Come mi sento trista! Come mi sento sola... É al di ripenso...

(cc. $1-17$ )
¡No obstante, pobre de mi, qué cambio ahora que la hora es fatal, yo estoy callada. en vela $y$ sin noticias, sin una dulce palabra! ¿Qué triste me siento, estoy tan sola\} Hoy reflexiono... 
Adjetivos: reflejan el estado de ánimo de la protagonista.

Verbos: la acción en esta sección es estática.

Ejemplo 2. Los adjetivos cc. 11-17.
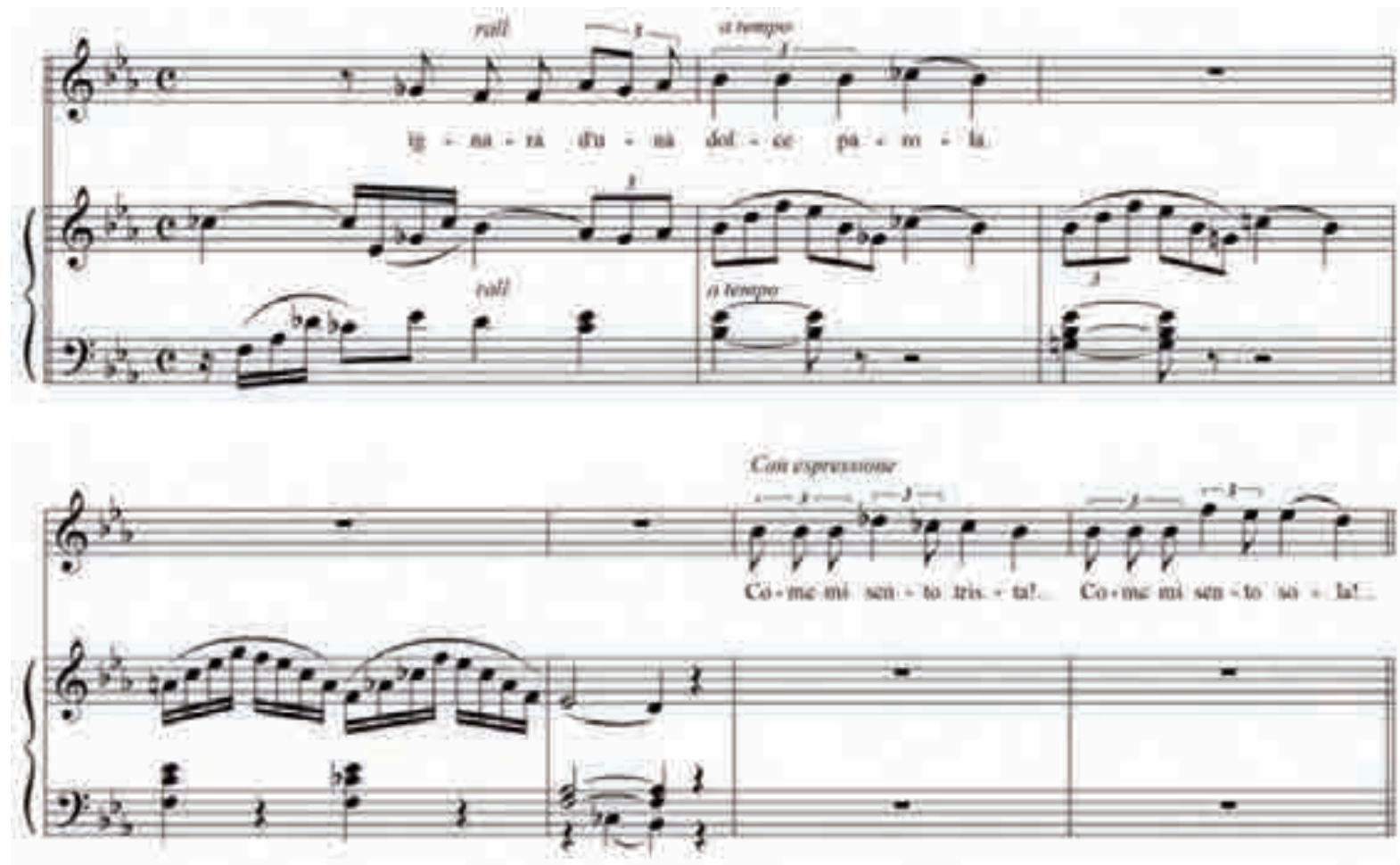

Analisis del texto $\mathrm{Al}$ memore di cuanto più inferiva

\begin{tabular}{|c|c|}
\hline $\begin{array}{l}\text { Al memore di cuanto } \\
\text { più inferiva, } \\
\text { su noi le truce ostit baldanza. } \\
\text { Nel villaggio scesa già noi fanciulle } \\
\text { Un'orda ebra ghermiva, ma um giovin } \\
\text { duce forse nostra difesa, e a noi salvo } \\
\text { clemente, é vita e onor. (cc. } 18-34 \text { ) }\end{array}$ & $\begin{array}{l}\text { Con este recuerdo de cuánto más se dediciá, } \\
\text { senti sobre nosotros la cruel y hostil osadia. } \\
\text { Del caserio bajaban los muchachos, un } \\
\text { grupo de ebrios me atrapó, pero un joven } \\
\text { caudillo llegó en nuestro auxilio y clemente } \\
\text { nos salvó. en vida y honor. }\end{array}$ \\
\hline
\end{tabular}

Adjetivos: expresan los malos recuerdos

de eventos ocurridos.

Verbos: refieren acontecimientos del pasado. 


\section{INFORMES DE INVESTIGACIÓN}

\section{Ejemplo 3. Adjetivos}
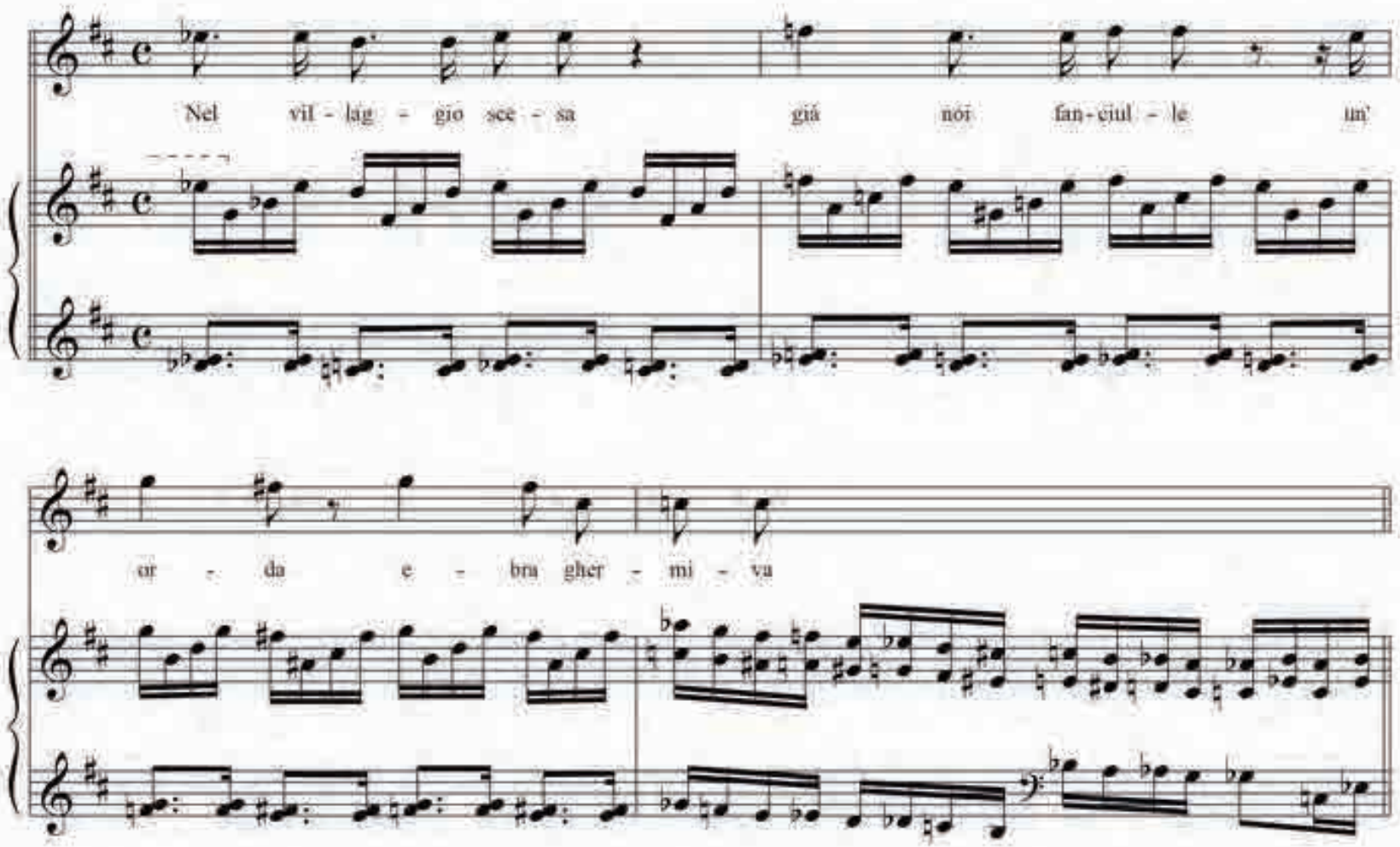

L.a prima volta un fascino Novo mi vinse el core, e del prode limmagine sculta rimane in me. (cc. $35-51$ )
Por primera vez vence a mi corazón una nueva fascinación y la imagen valerosa permanece esculpida en $\mathrm{mi}$.

Adjetivos: describen la impresión que le causó el objeto amado. Verbos: señalan el descubrimiento y lo relevante de sus sentimientos.

Ejemplo 4. Adjetivos cc. 35-38

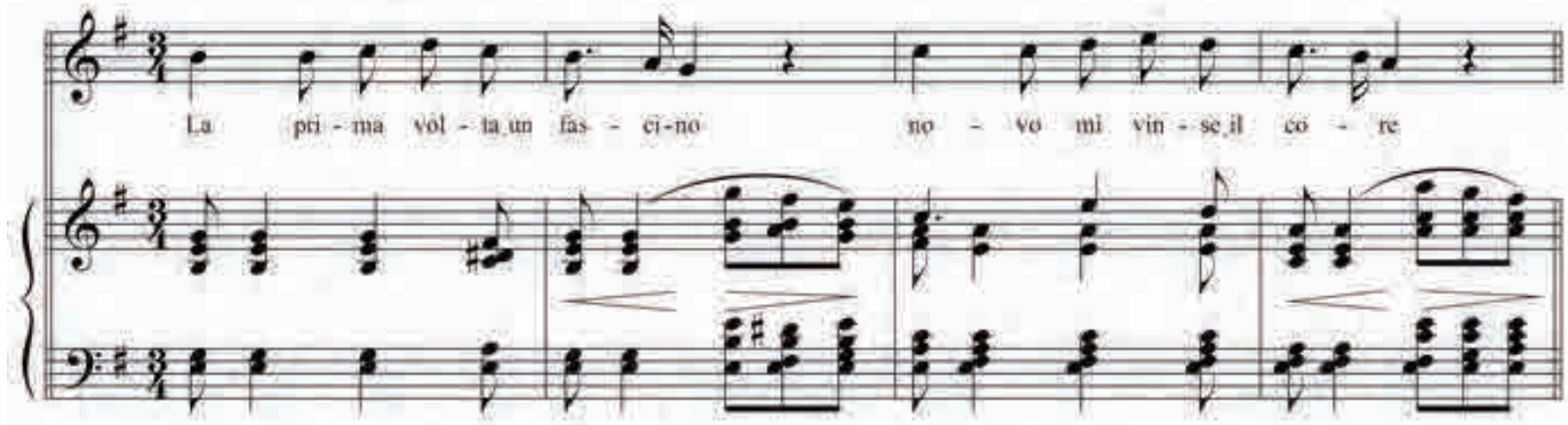


Ah! Si, cui dentro io porto diessa pasione il fuoco, il cui fin mi spaventa e giungerá, si fra poco. (cc. $51-60)$

Adjetivos: no utiliza.

Verbos: reflejan estado anímico, el verbo en futuro denota una premonición.

Ejemplo 5. Los verbos cc. 51-54

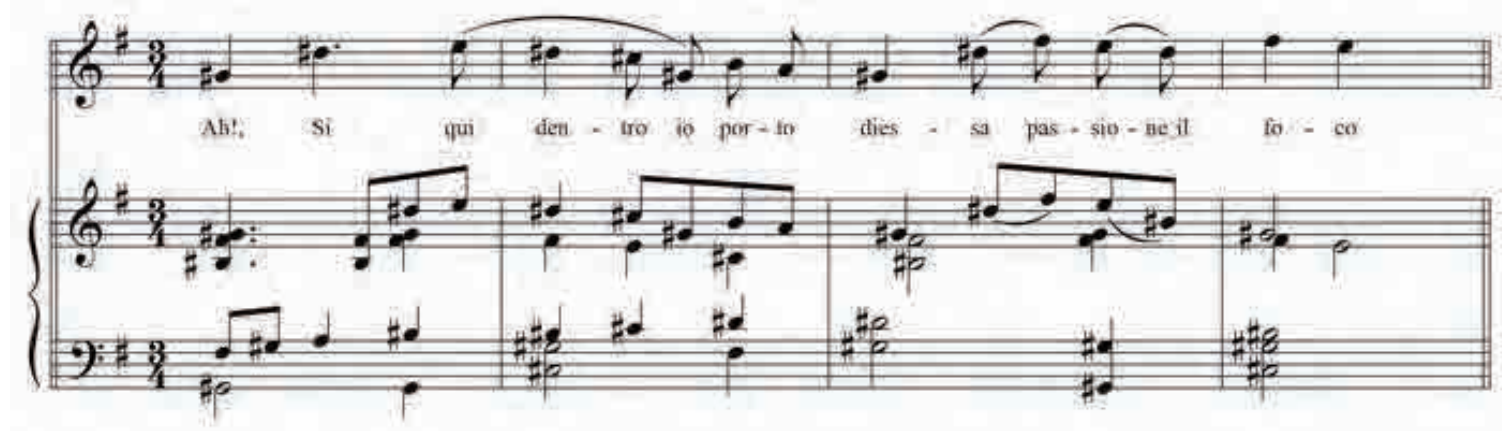

Crudel destin il mio

Ohime, perche ti vidi giovane stranier? (cc. $61-85$ )

Adjetivos: definen la relación entre los dos personajes.

Verbos: señala lo estático de la situación.

\section{Ejemplo 6. Adjetivos 61-65}

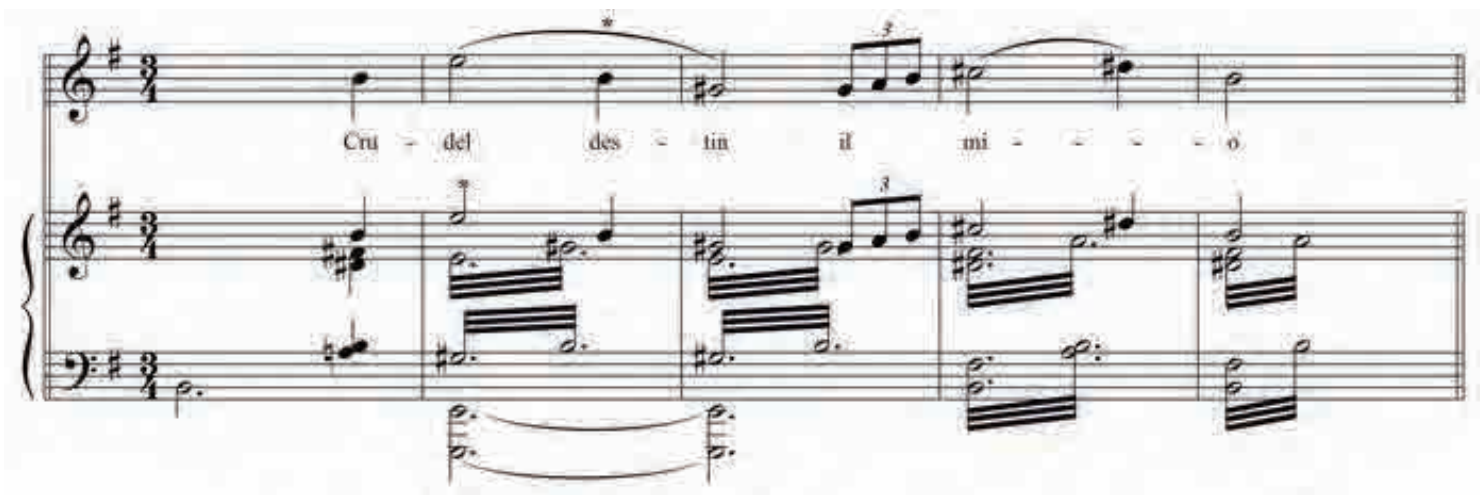




\section{INFORMES DE INVESTIGACIÓN}

\section{Algunas consideraciones}

Como podemos notar, una de las cosas que más apasionaban a Morales era el canto y en una carta a "El Nacional" fechada en mayo de 1883, nos dice cuál es el objeto de este:

Considerado como arte, el objeto del canto de la voz humana es el de expresar aquellas melodías y aquellos afectos, que corresponden al sentimiento de la composición musical y poética.

En este mismo escrito nos da una clara visión de las cualidades, que para él, que debe tener una voz y como se tiene que interpretar su música:

Todas las artes y por consecuencia también la música, tienen su parte mecánica y técnica, y otra que no se puede demostrar con reglas. En el arte del canto pertenecen a la primera todas las buenas cualidades de la voz, la cual debe de ser sonora, clara, bien timbrada, llena, entonada, ágil, flexible, robusta, grata, dulce, rica de extensión, etc.; el arte de modularla y emitirla amplia y llena; el pleno conocimiento de los recursos de la respiración; el saber prolongar el sonido más allá de su duración ordinaria, con el auxilio de una buena emisión del aliento; el saber tomar éste imperceptiblemente; el ligar los sonidos, crecerlos y disminuirlos por grados insensibles; destacarlos, acentuarlos; el pasar con destreza de la voz de pecho a la de cabeza y viceversa; el igualar los sonidos de un registro con los del otro ; una clara pronunciación; una buena articulación; la perfecta observancia del tiempo; la justa modulación en los ornamentos siempre análogos a la armonía; la prontitud de la lectura de las notas; la aptitud en el conocimiento del idioma. La segunda parte del canto consiste en animarlo y caracterizarlo de tal modo, que resulte la justa expresión análoga a los varios sentimientos, lo cual supone una rica fantasía, una libre y franca imaginación, la íntima penetración de una parte dada para que sea interpretada con todas la modificaciones de que sea susceptible y pueda obrar eficazmente en el corazón del auditorio.

\section{Conclusiones}

La extensa información recopilada a lo largo de la segunda mitad del siglo XIX y del primer cuarto del siglo XX ha olvidado, sin embargo, hacer hincapié en una serie de factores fundamentales relacionados con el entorno social como son la historia, la política, la economía y la identidad. Los textos que aportan información sobre la representación dramática, llámese ópera o la zarzuela, de este período no contienen más que datos duros que ilustran la actividad y el gusto de la época por estos génerosı. La nueva visión de la musicología, algunas ramas de la sociología cultural e incluso de la filosofía nos permiten comentar la música con una visión global del fenómeno sonoro y no solo analizarlo y/o interpretarlo fuera de su contexto. Es necesario tomar en cuenta las características particulares del entorno en el que fueron compuestos los manuscritos que ya tenemos al alcance para, de esta manera, reconstruir el rompecabezas musical del país a través de la reposición sonora de los rescates realizados, además de propiciar la transversalidad del conocimiento que rodea la obra musical. Necesitamos "jugar" en los dos roles: como investigador e intérprete para lograr rescates e interpretaciones documentadas en el entorno histórico-social y ofrecer a la audiencia versiones de calidad que fomenten la creación de público al hecho sonoro. 


\section{Bibliografía}

Appia, A. (1986). La Música y la puesta en escena. Madrid: Siruela.

Bellinghausen, K. (1999). Melesio Morales. Catálogo de Música. México: INBA.

Grier, J. (2008). La edición crítica de música historia método y práctica. Madrid: Akal.

Herrera y Ogazón, A. (1992). El arte musical en México. México: CONACULTA - INBA CENIDIM.

Maya, A. (1992). Una aproximación a Anita, ópera de Melesio Morales. Hetereofonía(107) Maya, A. (1994). Melesio Morales, labor periodística. México: CENIDIM.

Maya, A. (2013). La herencia cultural de la ópera mexicana del siglo XIX. En Miranda, R., Tello, A. (Coords.) La música en los siglos XIX y XX. México: CONACULTA.

Miranda, R. (1996). La zarzuela en España e Hispanoamérica. Centro y Periferia, 1800-1950. Cuadernos de Música Iberoamericana (2).

Miranda, R. (1997). La zarzuela en España e Hispanoamérica. Centro y Periferia, 1800-1950. Cuadernos de Música Iberoamericana (3).

Miranda, R. (1999). El espejo idealizado: un siglo de Ópera en México (1810-1910). Madrid: ICCUM.

Morales, M. (s/a). A, B, C Método teórico-práctico de Solfeo. México: H. Nagel sucesores. Morales, M. (1999). Mi libro verde de apuntes e impresiones. México: CONACULTA.

Olavarría y Ferrari, E. (1961). Reseña histórica del Teatro en México. (Vol. IV). México: Porrúa.

Olavarría y Ferrari, E. (1961). Reseña histórica del Teatro en México. (Vol. V). México: Porrúa.

Olavarría y Ferrari, E. (1961). Reseña histórica del Teatro en México. (Vol. VI). México: Porrúa.

Pulido Granata, R. (1970). La tradición operística en la ciudad de México (siglo XIX). México: SEP.

Reyes de la Maza, L. (1965). El teatro en México. México: Instituto de investigaciones estéticas-UNAM.

Romero, J. (1950). C. Chopin en México. México: UNAM.

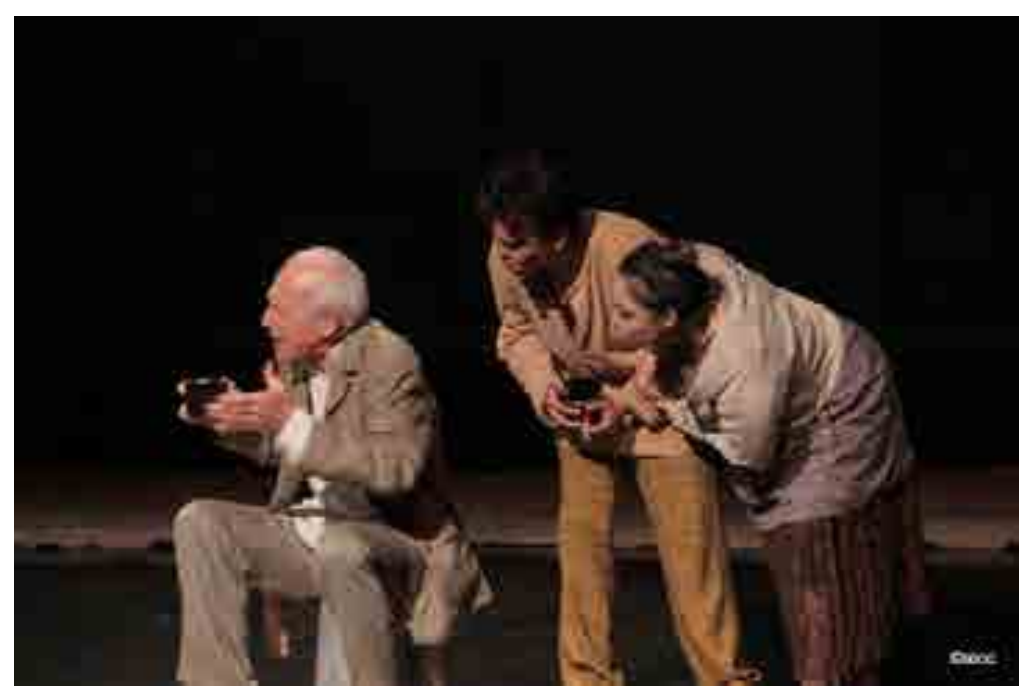

